\title{
SIMULATION OF WORM-LIKE MACHINE
}

\author{
KELEMEN Michal' ${ }^{1}$, GMITERKO Alexander ${ }^{1}$, HRONCOVÁ Darina ${ }^{1}$ \\ ${ }^{1}$ Technical University of Košice, Faculty of Mechanical Engineering, Department of Mechatronics, Park \\ Komenského 8,04200 Košice, Slovak Republic,email: michal.kelemen@tuke.sk
}

\begin{abstract}
The paper deals with bristled in-pipe machine simulation. Simulation model is developed and experimentally identified properties are added into the model to achieve high coincidence of the model with real machine. Simulation gives the answers to some selected problems.
\end{abstract}

KEYWORDS: In-pipe machine, bristle, in-pipe locomotion, friction difference

\section{Introduction}

Currently many engineering systems include also pipe systems for various purposes as gas and liquids transferring, heat and energy systems, shielding device for other systems. Material degradation and damage can occur in pipe wall. Almost every pipe system needs any inspection of actual state as the prevention of leakage of transferred medium and next disasters. This prevention is much easier and cheaper than removal of far-reaching disasters consequences. The energy systems like steam generators have to be periodically checked for cracks in pipe wall. Pipe systems are also used as place for installing of cables or other systems. Several companies use the cable drawing pipe robots as alternative to general site excavation. Site excavation is very expensive and needs long time of realisation.

There are several kinds of machines developed in the world, which are dedicated for many tasks like in-pipe inspection, pipe repairing, wires installing into existing pipes etc. The solved machine is dedicated to locomotion inside the pipe and for specified relevance tasks. These machines can be divided into two main groups following the inner pipe diameter: macro-pipe machines and micro-pipe machines, which are also called as "in-pipe machines". Another way of dividing is under the way of locomotion. So it is possible to divide into two main groups: "biologically inspired and synthetic in-pipe machines".

This paper deals with "bristled in-pipe machine", which belongs to group of biologically inspired locomotion. The principle is coming from worm like locomotion, which is based on fact that machine body is still in contact with pipe wall via two groups of bristles, which are arranged at angle to the pipe axis. The friction between bristle tip and inner pipe wall has the directional character that is the forward moving is easier then backward moving. The machine changes the distance between these groups, and mentioned directional character of friction causes, that machine locomotes inside pipe.

The main topic of this paper is to design of the machine model and simulations with this model. The friction between the bristle tip and pipe wall is experimentally identified and these dependencies are inserted into the model. Several problems, which are necessary to solve, are identified [1 - 9]. 


\section{Concept of the machine}

The in-pipe machine (Fig. 1) locomotes via worm-like principle described above. It consists of a piezoactuator (1), which converts electrical energy form to mechanical energy form. Just piezoactuator transformation cannot provide in-pipe locomotion. So there is a need of other mechanical parts - bristle plate $(2,3)$ and bristles (4). These mechanical parts add another function to piezoactuator. Energy transformation can be controlled with any microcontroller. Finally, locomotion can be obtained with this synergic integration.

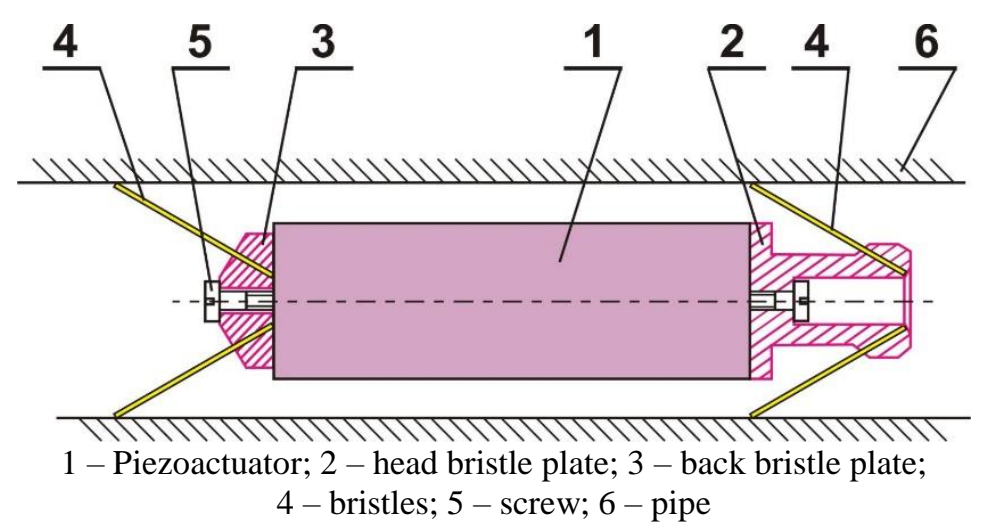

Fig. 1 The simplified machine organs and parts arrangement

\section{Machine model}

The in-pipe machine model is coming out from Fig. 1. The overall machine mass is concentrated into two masses $m_{1}$ a $m_{2}$ (Fig. 2), which consist of bristle block mass and half of main actuator mass. It is possible, because of low weight of main actuator compared with another parts. The piezoelectric stacked actuator is selected as the main actuator. The actuator is represented with own stiffness $k_{p}$ and generated forces $F_{1}$ and $F_{2}$. Friction between the pipe and bristle tips are represented with forces $F_{t 1}$ a $F_{t 2}$, which depends on velocity and direction of moving. Paths of masses $x_{1}$ a $x_{2}$ are the main topic of exploration.

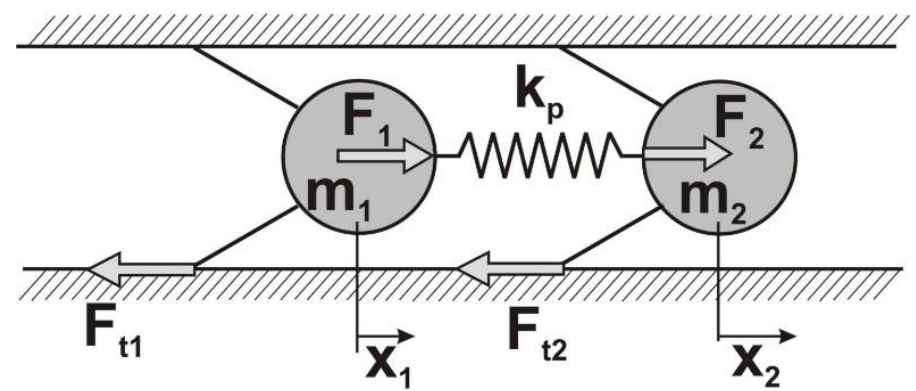

Fig. 2 Machine model

The model on Fig. 2 can be described with these equations:

$$
\begin{gathered}
F_{1}-k_{P} \cdot\left(x_{1}-x_{2}\right)-F_{t 1}=m_{1} \cdot \ddot{x} \\
F_{2}-k_{P} \cdot\left(x_{2}-x_{1}\right)-F_{t 2}=m_{2} \cdot \ddot{x}_{2}
\end{gathered}
$$

where

$$
F_{1}, F_{2} \quad-\quad \text { excitation force (sine wave), where } F_{1}=F_{2}
$$




$$
\begin{array}{ll}
F_{t 1}, F_{t 2} & \text { - friction force between the bristle tip and inner pipe wall for mass } 1 \text { and } 2 \\
k_{p} & \text { - actuator stiffness } \\
x_{1}, x_{2} & \text { - paths of masses } 1 \text { a } 2 \\
\ddot{x}_{1}, \ddot{x}_{2} & \text { - acceleration of masses } \\
m_{1}, m_{2} & \text { - weight of masses } 1 \text { and } 2
\end{array}
$$

If the in-pipe machine doesn't locomote, there is only normal force, which is applied to inner pipe wall. The normal force depends on bristle deflection, bristle stiffness and assembling bristle angle. When excitation force will be applied and it will be continuously increased, if machine starts locomotion, value of the excitation force will be equal to adhesive part of friction force $F_{t o}$.

Bristles are also used as part for creating force coupling with inner pipe wall. Diagonally bristle attaching is suitable because of anisotropic character of friction between bristle tip and pipe wall. The friction force in forward direction is less than friction force in backward direction. The difference of these friction forces causes the forward locomotion of in-pipe machine.

There is a need to identify the friction forces. It is assumed that friction force depends on locomotion velocity (it means the value and direction) of the machine. Friction force identification is able also to confirm the existence of mentioned friction difference, which is the base of this locomotion principle.

\section{$4 \quad$ Machine simulation}

The simulation model of in-pipe machine is developed on the base of equation (1) and (2) in Matlab - Simulink environment. There are three types of bristle, which are inserted into simulation model (cross-section - round, rectangular and double round).

The main goal of simulation is confirmation of friction difference between the bristle tip and pipe wall. Other questions are:

How is the influence of viscous part of friction?

Which type of bristle is better? Etc.

The Stribeck model is chosen as base for friction force description. This model contains the area of discontinuity for low locomotion velocities. This interpretation causes some numeric problems in simulation process. It was the reason for small modification of this friction model (Fig. 2). Width of interval $\left(\varepsilon_{1}, \varepsilon_{2}\right)$ converges to zero.

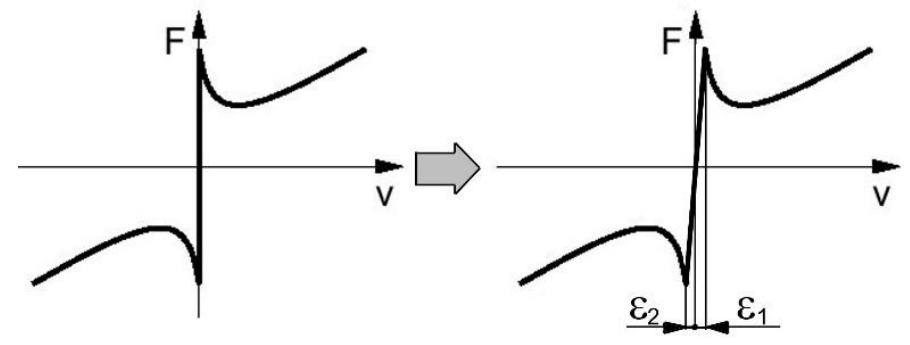

Fig. 3 Model of friction force between the bristle tip and pipe wall 
Fig. 4 shows the simulation block model of the machine with adhesive part of friction. The actuator has harmonic voltage on its input following the piezo producer instructions. The model is represented with blocks of type Gain (number of piezo plates, $d 33$ and its stiffness) and Sum. It is only simple model of piezoactuator. It can be changed with any different actuator, which is able to produce rectilinear moving. The main part of machine model contains the masses $m_{1}$ and $m_{2}$ and integrators (integrator and integratorl) for identification of paths $x_{1}$ and $x_{2}$.

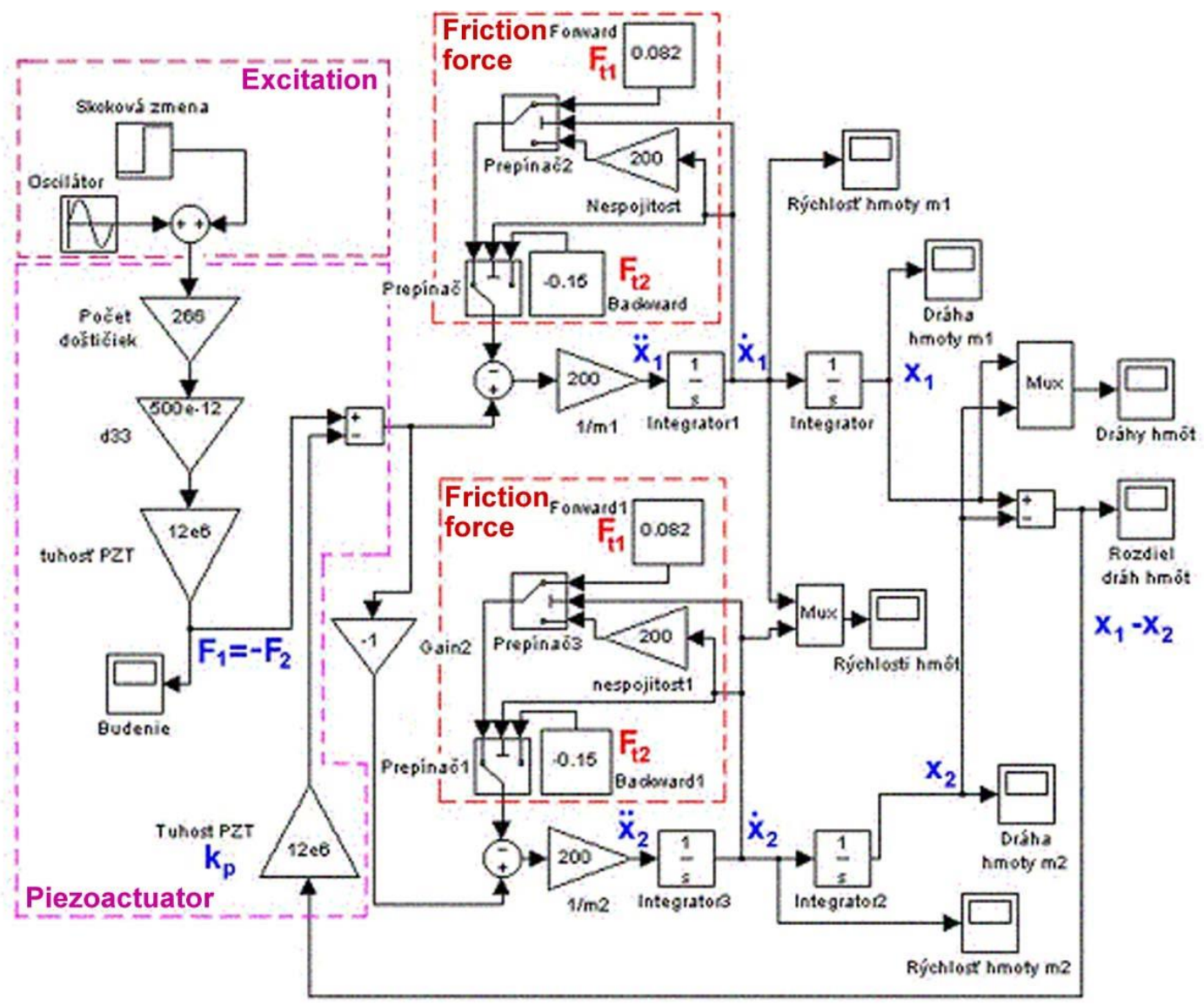

Fig. 4 Simulation model of in-pipe machine with adhesive part of friction force

Blocks (Forward, Forward1, Backward a Backward1) are the coefficients of adhesive part of friction for forward and backward moving. Realisation of discontinuous friction model is with blocks (Prepinač, Prepinač 1, Prepinač2, Prepinač3), which select the value of coefficient following the moving velocity of the mass $m_{1}$ and $m_{2}$.

Visualisation of selected quantities is via block Scope and multiply registration is achieved with block of multiplexer (MUX).

Model (Fig.5) has both adhesive and viscous part friction. Consequently, if we compare the results of simulation model (Fig. 4) and (Fig. 5), we can discover the influence of viscous part of friction.

Fig. 6 shows dependence of paths of masses $m_{1}$ a $m_{2}$ in time for the machine with round bristles (assumption of three bristles in front and back block of bristles). As it shown, there is also regressive motion, but overall locomotion is in forward direction. Fig. 6 confirms the existence of friction difference between friction forces in forward and backward moving. 
Fig. 7 shows the dependence of velocities of machine masses in time. These velocities have reversed phases.

Fig. 8 shows the influence of viscous part of friction between the bristle tip and pipe wall. Inserting of viscous friction part causes only the shift of initial deformation of piezoactuator, but there is no influence to increment of travelled path. So, it is possible to ignore it in simulation model.

Fig. 9 shows that the machine with round bristle is faster. It is important to say that the real machine is also influenced by another factor as contact phenomena etc.

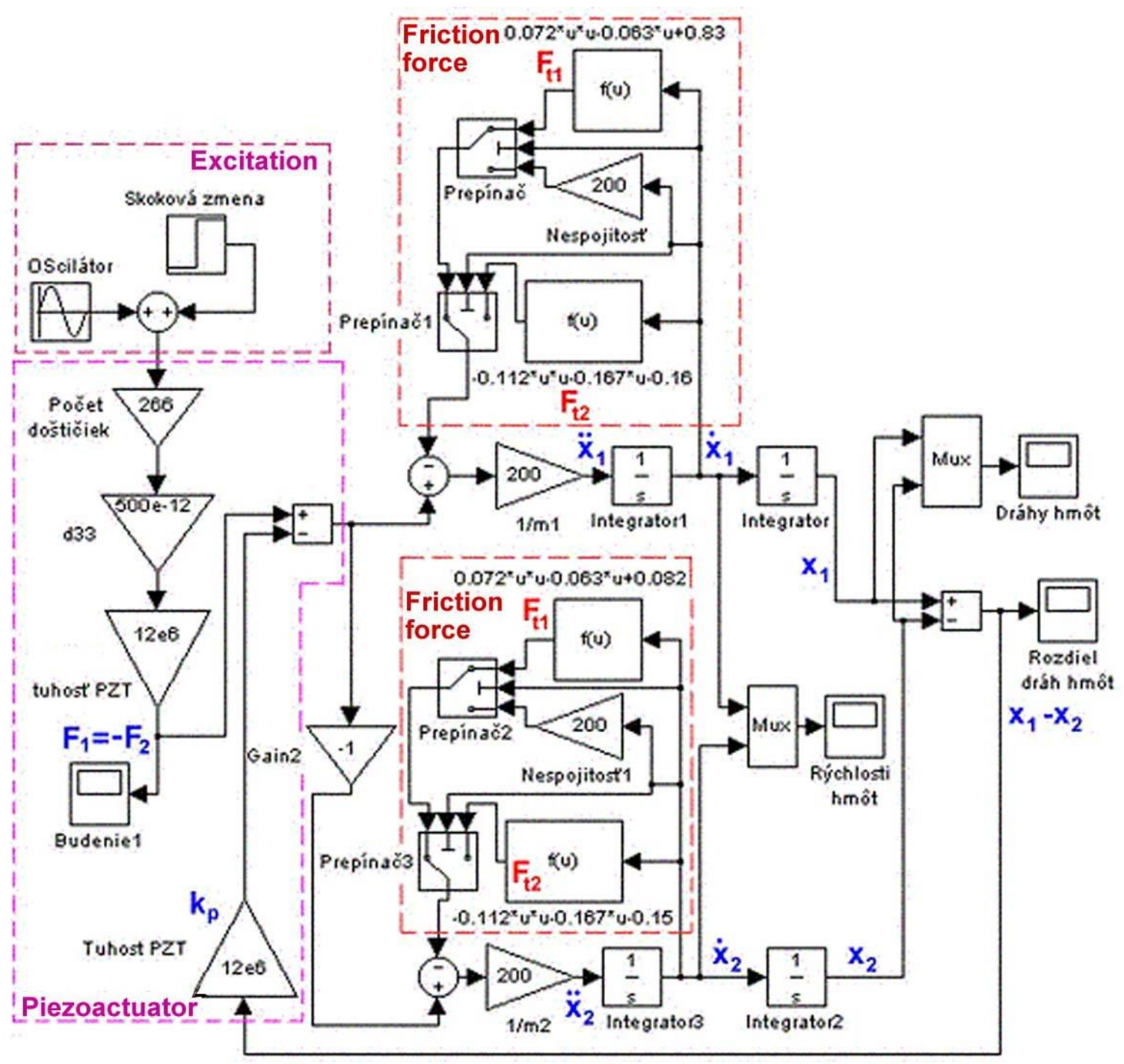

Fig. 5 Simulation model of in-pipe machine with adhesive and viscous part of friction force 


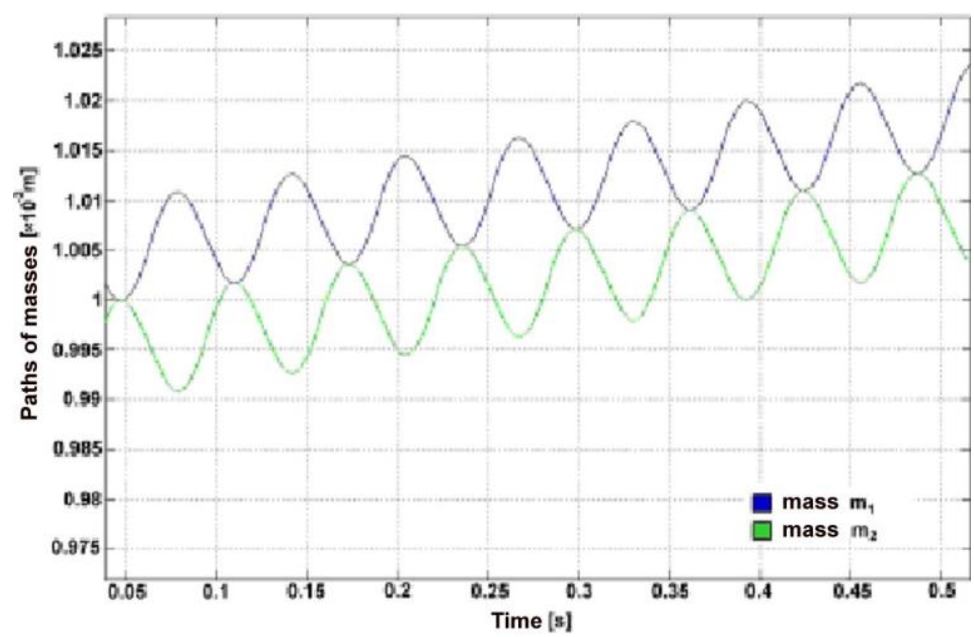

Fig. 6 Paths of masses $m_{1}$ and $m_{2}$ versus time for machine with round bristles (Assumption of three bristles in front and back block of bristles)

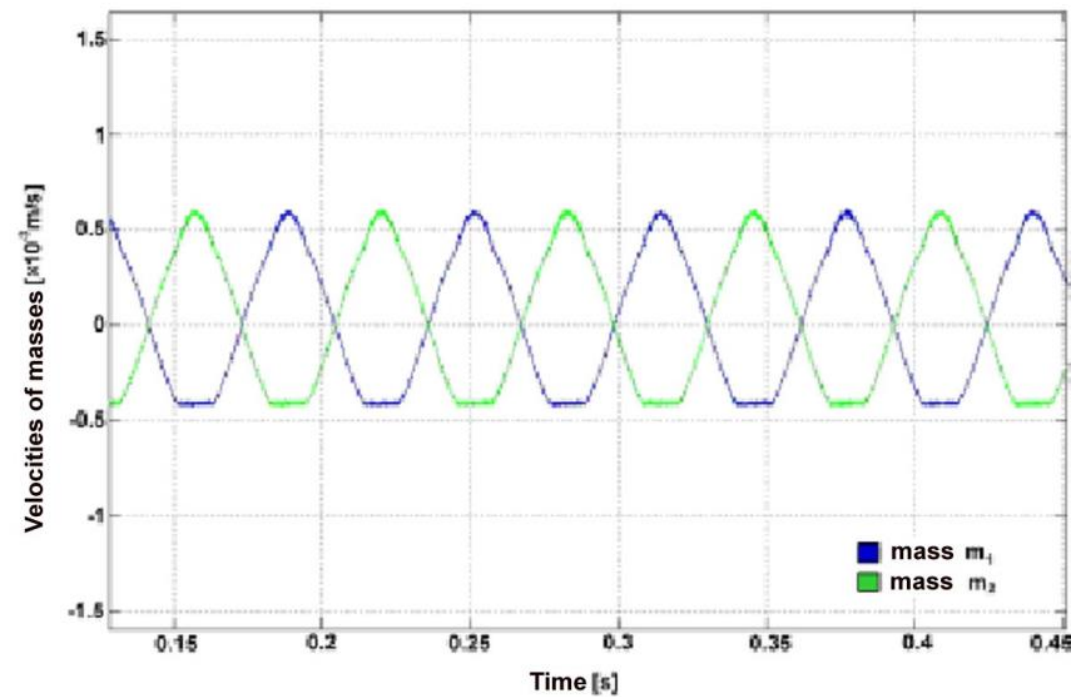

Fig. 7 Velocities of masses $m_{1}$ and $m_{2}$ versus time for machine with round bristles (Assumption of three bristles in front and back block of bristles) 


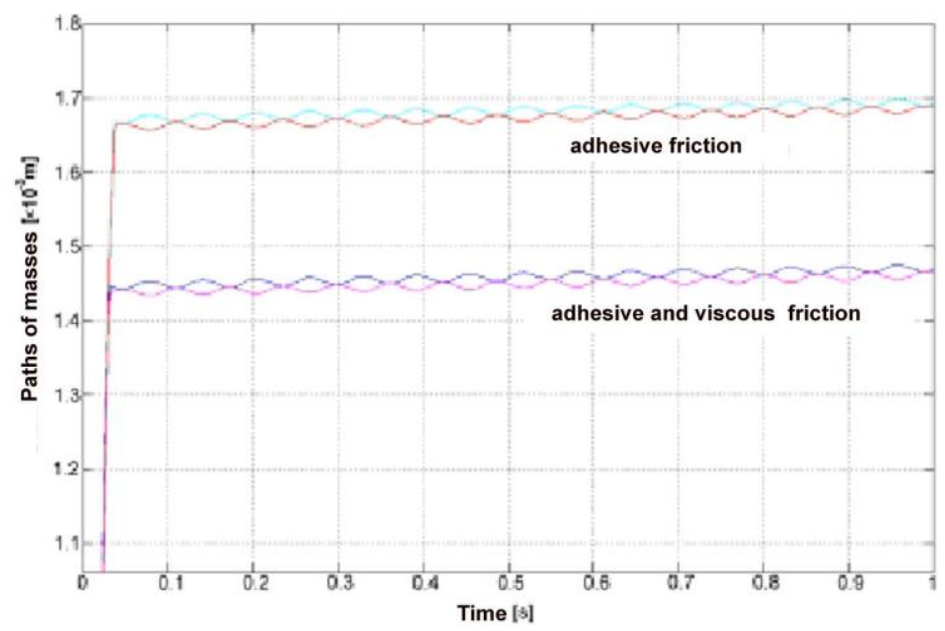

Fig. 8 Paths of masses $m_{1}$ and $m_{2}$ versus time for machine with and without viscous part of friction (Assumption of three bristles in front and back block of bristles)

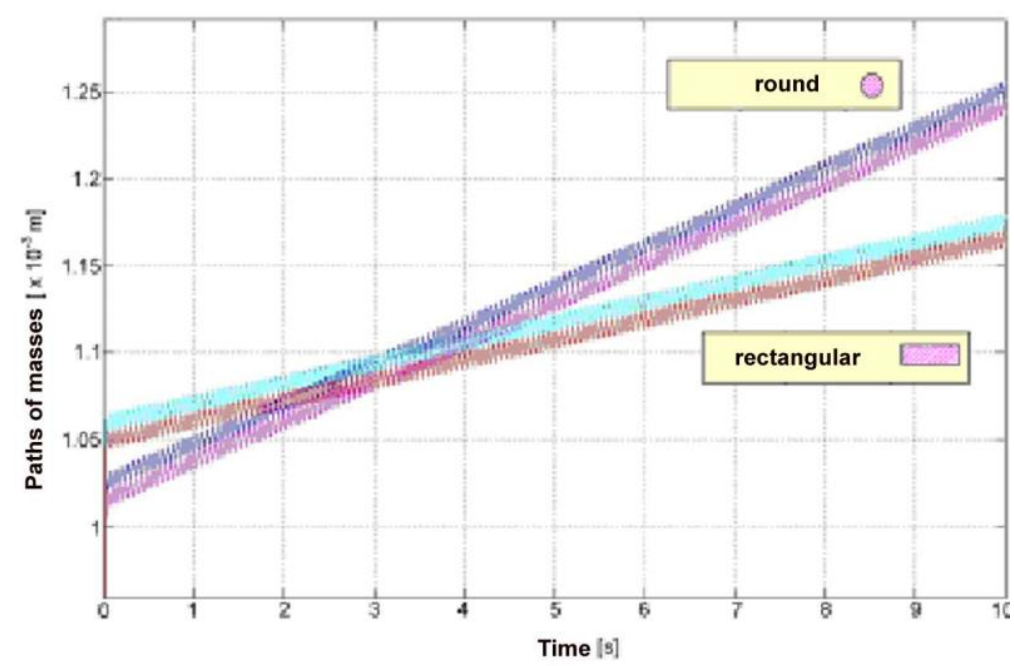

Fig. 9 Paths of masses $m_{1}$ and $m_{2}$ versus time for machine with round and rectangular bristles (Assumption of three bristles in front and back block of bristles)

On the base of simulation result, the experimental model (Fig. 10) of machine has been built. The linear electromagnetic motor has been used instead of piezoactuator as drive unit, but friction difference principle is the same. The model enables to verify the simulation results. 

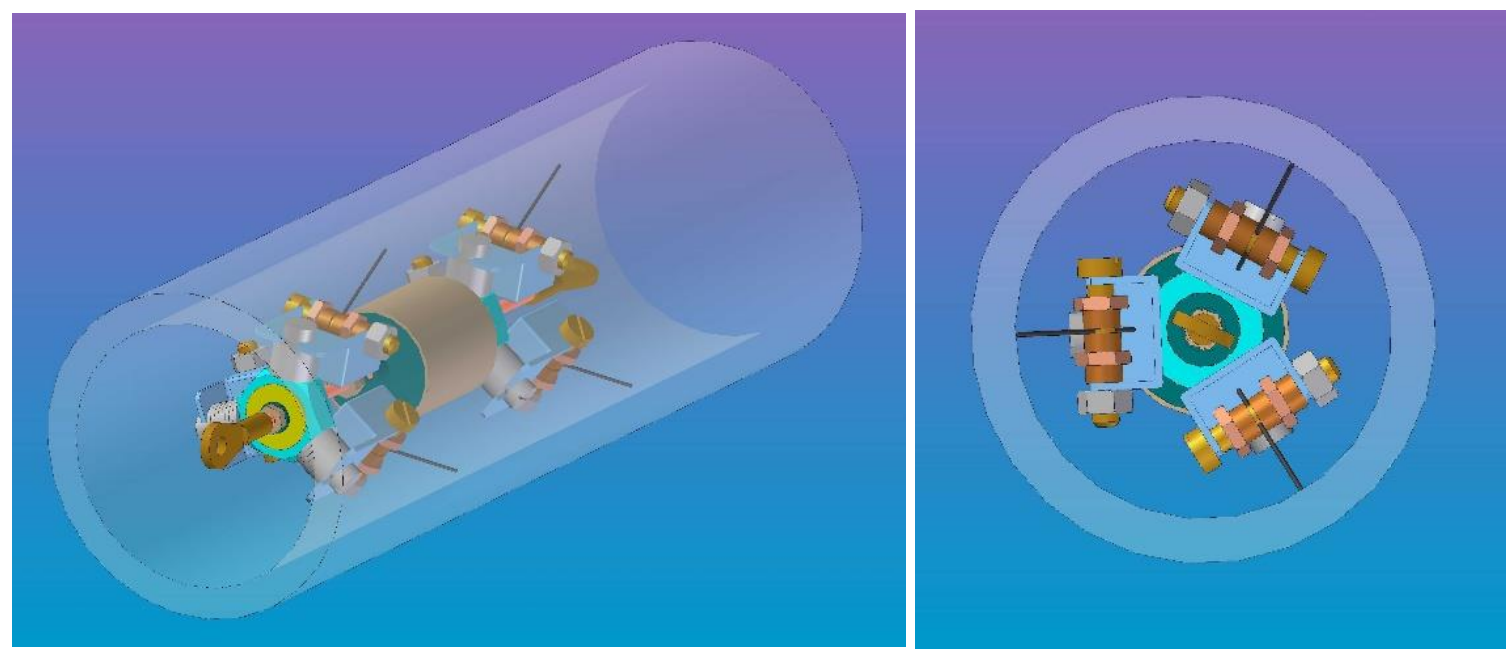

Fig. 10 Experimental machine model

\section{CONCLUSION}

Simulation results confirm existence of friction difference but there is also regressive motion. It means that part of energy is used for unprofitable motion. The round bristles are more suitable for the machine than rectangular. Probably, there is also high influence of contact phenomena, wearing etc. In the next it is necessary to append the influence of bristles angle into the model. It is very complicated, because of high deformation of bristles.

Mechanical parts provide force coupling with inner pipe wall and diagonally attached bristles, which cause anisotropic character of friction force between bristle tip and pipe wall.

The control system, which generates suitably modulated voltage, provides actuator controlling. There is a need of organs and parts optimisation for effective utilisation of energy transformation. Hence, mechatronics design approach is necessary. It means that actuator is supported with mechanical part and controlling. Another possible way of improving is to add another function to bristles. Implementation of another actuator gives new function to bristles. This actuator is able to drive bristle parameters, and these bristles become an intelligent "smart bristles". Bristle properties cannot be improved, moreover, by classic design approach, so there is a place for intelligence integration. Finally, the integration gives better properties to system, which becomes competitive in this class of machine.

Model based design has key role in mechatronic product design. This approach can improve design and also design time is shorter. The main advantage of this approach is that all weakness can be observed in early stage of design and can be solved early [10 - 16].

\section{ACKNOWLEDGEMENT}

This work was supported in part by the Grant Agency VEGA of the Slovak Ministry of Education Grant 1/0872/16 and 1/0389/18. 


\section{REFERENCES}

[1] S. Aoshima et al. A miniature mobile robot using piezo vibration for mobility in a thin tube. ASME J. Dynam. Syst., Meas., Contr. 1993 (115), 270-278.

[2] T. Idogaki et al., Characteristics of piezoelectric locomotive mechanism for an in-pipe micro inspection machine. In Proc. IEEE 6th Int. Symp. Micro Machine and Human Sciences 1995, 193 - 198.

[3] Linzhi Sun Ping Sun Xinjie Qin Cunmin Wang. Micro Robot in Small Pipe with Electromagnetic Actuator. Proceedings of the 1998 International Symposium on Micromechatronics and Human Science 1998, 243 - 248.

[4] T. Matsumoto et al. A prototype model of micro mobile machine with piezoelectric driving force actuator. In Proc. IEEE 5th Int. Symp. Micro Machine and Human Sciences 1994, $47-54$.

[5] T. Fukuda, H. Hosokai, M. Uemura. Rubber gas actuator driven by hydrogen storage alloy for in-pipe inspection mobile robot with flexible structure. In Proc. IEEE Int. Conf. Robotics, Automation 1989 (3), 1847 - 1852.

[6] S. Iwashita, I. Hayashi, N. Iwatsuki, K. Nakamura. Development of in-pipe operation micro robots. In Proc. IEEE 5th Int. Symp. Micro Machine and Human Sciences 1994, $41-45$.

[7] A. Degani, S. Feng, H. Choset, M. T. Mason. Minimalistic, Dynamic, Tube Climbing Robot. In Proc. of 2010 IEEE Int. Conf. on Robotics and Automation Anchorage Convention District, May 3-8, 2010, Anchorage, Alaska, USA, 2010, 1100 - 1101.

[8] A. Gmiterko, M. Dovica. Dependence of the Body Sensitivity Function on Geometrical Size for the Mechatronic System. International Conference Mechatronics and Robotics' 97. 29.9.- 2. 10. 1997, Brno, Czech Republic, 1997, 27 - 30.

[9] M. Dovica, A. Gmiterko. To some Questions of Components and Modules of Mini and Micromechanisms. Mechanics '98. Proceedings of the International Scientific Conference. Volume I, Rzeszow University of Technology, Poland, 1998, 191 - 198.

[10] A. Vitko, L. Jurišica, M. Kl'účik, F. Duchoň. Context Based Intelligent Behaviour of Mechatronic Systems. Acta Mechanica Slovaca. 2008 (12), No. 3-B., 907 - 916.

[11] P. Pásztó, P. Hubinský. Mobile robot navigation based on circle recognition. Journal of Electrical Engineering 2013 (64), No. 2, 84 - 91.

[12] I. V. Abramov, Y. R. Nikitin, A. I. Abramov, E. V. Sosnovich, P. Božek. Control and Diagnostic Model of Brushless DC Motor. Journal of Electrical Engineering 2014 (65), No. $5,277-282$.

[13] D. Koniar, L. Hargaš, S. Štofan. Segmentation of Motion Regions for Biomechanical Systems. Procedia Engineering 2012 (48), 304 - 311.

[14] F. Duchon, P. Hubinský, J. Hanzel, A. Babinec, M. Tölgyessy. Intelligent Vehicles as the Robotic Applications. Procedia Engineering 2012 (48), 105 - 114.

[15] P. Božek. Robot path optimization for spot welding applications in automotive industry, Tehnicki vjesnik / Technical Gazette . Sep/Oct2013, Vol. 20 Issue 5, p 913-917. 5p.

[16] F. Trebuňa, F. Šimčák. Elasticity, strength and plasticity in mechanical engineering. Edition of scientific and special publications - Faculty of Mech. Eng. TU in Kosice, Emilena, Košice 2005. ISBN 80-8073-276-0. 
[17] J. Úradníček, P. Kraus, M. Musil, M. Bachratý. Investigation of frictional stick-slick effect in disk brake NVH. Journal of Mechanical Engineering - Strojnícky časopis, 2017 (67), No. 1, 93 - 100.

[18] P. Staňák, J. Sládek, V. Sládek. Analysis of piezoelectric semiconducting solids by meshless method, Journal of Mechanical Engineering - Strojnicky časopis 2015 (65), No. $1,77-92$. 